\title{
Predictors of change in objectively measured and self-reported health behaviours among individuals with recently diagnosed type 2 diabetes: longitudinal results from the ADDITION-Plus trial cohort
}

Laura Kuznetsov' ${ }^{1}$, Rebecca K Simmons', Stephen Sutton², Ann-Louise Kinmonth², Simon J Griffin 1,2, Wendy Hardeman ${ }^{2^{*}}$ on behalf of the ADDITION-Plus study team

\begin{abstract}
Background: There is limited evidence about predictors of health behaviour change in people with type 2 diabetes. The aim of this study was to assess change in health behaviours over one year and to identify predictors of behaviour change among adults with screen-detected and recently clinically diagnosed diabetes.

Methods: ADDITION-Plus was a randomised controlled trial of a behaviour change intervention among 478 patients (40-69 years). Physical activity and diet were measured objectively (physical activity at 1 year) and by self-report at baseline and one year. Associations between baseline predictors and behaviour change were quantified using multivariable linear regression.
\end{abstract}

Results: Participants increased their plasma vitamin $C$ and fruit intake, reduced energy and fat intake from baseline to follow-up. Younger age, male sex, a smaller waist circumference, and a lower systolic blood pressure at baseline were associated with higher levels of objectively measured physical activity at one year. Greater increases in plasma vitamin C were observed in women (beta-coefficient [95\% Cl]: beta $=-5.52[-9.81,-1.22]$ ) and in those with screen-detected diabetes (beta $=6.09[1.74,10.43])$. Younger age predicted a greater reduction in fat $($ beta $=-0.43[-0.72,-0.13])$ and energy intake (beta $=-6.62[-13.2,-0.05])$. Patients with screen-detected diabetes (beta $=74.2[27.92,120.41])$ reported a greater increase in fruit intake. There were no significant predictors of change in self-reported physical activity. Beliefs about behaviour change and diabetes did not predict behaviour change.

Conclusions: Older patients, men and those with a longer duration of diabetes may need more intensive support for dietary change. We recommend that future studies use objective measurement of health behaviours and that researchers add predictors beyond the individual level. Our results support a focus on establishing healthy lifestyle changes early in the diabetes disease trajectory.

Keywords: Health behaviour, Behaviour change, Predictors, Type 2 diabetes, Newly diagnosed

\footnotetext{
* Correspondence: wh207@medschl.cam.ac.uk

${ }^{2}$ The Primary Care Unit, Cambridge Institute of Public Health, University of Cambridge, Robinson Way, Cambridge CB2 OSR, UK

Full list of author information is available at the end of the article
} 


\section{Background}

Regular physical activity (PA) and healthy eating confer metabolic and cardiovascular benefit for people with type 2 diabetes [1-4]. Exercise intervention significantly increases insulin response, improves glycaemic control, and decreases plasma triglycerides in people with established diabetes, while weight reduction significantly improves glycaemic control and lowers blood pressure and CVD risk [1]. Randomised controlled trials (RCTs) evaluating $\mathrm{PA} /$ or diet interventions among individuals with recently diagnosed diabetes (e.g. diagnosed in the last three years) report an improvement in glycaemic control and modelled CVD risk [5-7].

Despite the established benefits of a healthy lifestyle and its importance for the clinical management of diabetes, many people who have been diagnosed find it difficult to achieve and maintain changes in health behaviour $[8,9]$. There may be a window of opportunity to facilitate health behaviour change soon after diagnosis. This may vary according to the time elapsed since diagnosis and whether patients are detected through screening or diagnosed in routine clinical practice [10]. Recognising patients who are more or less likely to change their health-related behaviour after being diagnosed with diabetes, may offer the possibility of tailored support and inform the development of behavioural interventions. However, few previous studies have examined predictors of change in PA and diet among people with recently diagnosed diabetes. For example, results from an RCT examining a brief self-management intervention to support patients with recently diagnosed diabetes $(n=180)$ to achieve sustained improvements in their exercise and diet showed that participants with a higher proactive competence (e.g. initiating health behaviours, dealing with potential barriers to goal-maintenance) at baseline reported greater self-management and improvement in exercise and diet at 12 months [11]. Baseline exercise behaviour, body mass index (BMI) and dietary behaviour were also positively associated with exercise and diet at follow-up. A study with 6 months follow-up in a cohort of newly diagnosed patients $(n=204)$ revealed that younger individuals, men, and those who had positive beliefs about the long-term consequences of exercise behaviour were more likely to increase their PA [12].

The interpretation of previous studies is limited by the measurement of health behaviours using self-report [11-13], small sample size [11-13], short-term follow-up $[12,13]$, and examination of a limited range of predictors [11-13]. This makes it difficult to generalise results to patients with recently diagnosed diabetes. Using data from the ADDITION-Plus trial, which evaluated a behaviour change intervention among recently diagnosed diabetes patients with objective measurement of health behaviours and one year follow-up, we aimed to (i) assess change in health behaviours over one year and (ii) examine associations between baseline socio-demographic, clinical and psychological predictors, and change in health behaviours.

\section{Methods}

The design and rationale for the ADDITION-Plus trial have been reported previously [14]. In brief, ADDITIONPlus (2002-2007) is a randomised controlled trial nested within the intensive treatment arm of the ADDITIONCambridge study, which evaluated the efficacy of a facilitator-led, theory-based behaviour change intervention over and above intensive general practice team-led treatment among recently diagnosed patients with diabetes. Thirty four general practices (GP) in the East of England participated. Eligible individuals were those aged 40-69 years diagnosed with diabetes following screening in the ADDITION study [15] or clinically diagnosed during the three previous years in participating GP surgeries. Exclusion criteria included pregnant or lactating women or those with a likely prognosis of less than one year. Eligible participants $(n=478)$ were individually randomised to receive either intensive treatment alone $(n=239)$, or intensive treatment plus a behaviour change intervention delivered by trained facilitators at the patient's practice $(n=239)$. The intervention was designed to build on the diabetes education delivered by practice nurses and included a one-hour introductory meeting followed by individually tailored six 30-minute meetings and four brief phone calls during the one year period. Baseline measurements were carried out on all eligible patients including the completion of standardised self-report questionnaires, physiological and anthropometric measures, and venesection (including assessment of plasma vitamin C). Full details of these measurements are published elsewhere [14]. Similar measurements were conducted one year after recruitment, as well as objectively measured PA using a combined heart rate and accelerometry monitor. All participants gave written informed consent, and the study was approved by the Eastern Multi-Centre Research Ethics Committee (reference number: 02/5/54). The trial is registered as ISRCTN 99175498.

\section{Socio-demographics}

Standardised self-report questionnaires were used to collect information on age, sex, age left full-time education, employment and marital status, social class and ethnicity.

\section{Clinical measures}

Clinical measures were collected by trained staff following standard operating procedures. Waist circumference was estimated as the average of two measurements taken 
halfway between the lowest point of the rib cage and the anterior superior iliac crests while standing. Blood pressure was calculated as the mean of three measurements performed after 10 minutes rest, while participants were seated with the cuff on the predominant arm at the level of the heart, using an automatic sphygmomanometer (Omron M4, UK). Glycosylated haemoglobin $\left(\mathrm{HbA}_{1 \mathrm{c}}\right)$ was analysed in venous samples by ion-exchange highperformance liquid chromatography (Tosoh Bioscience, Redditch, UK). Serum total cholesterol was measured using enzymatic techniques (Dade Behring Dimension analyser, Newark, USA). Recommendations for the treatment and management of diabetes include a reduction and/or maintenance in levels of blood glucose $\left(\mathrm{HbA}_{1 \mathrm{c}}\right.$ between 6.5 and $7.5 \%$ ), blood lipids (total-cholesterol $<4.0 \mathrm{mmol} / \mathrm{L}$ ) and blood pressure (systolic $<140 \mathrm{mmHg}$ ) [16].

\section{Health behaviour measures}

Objectively measured PA was assessed at one year using a combined heart rate and accelerometry monitor (Actiheart, CamNtech, Cambridge, UK), which was worn continuously for at least four days [17]. A graded treadmill walk test was used to individually calibrate heart rate. Heart rate data collected during the free-living period were processed [18] and activity intensity $(\mathrm{J} / \mathrm{min} / \mathrm{kg})$ was estimated using a branched equation framework [19]. Resulting time-series data were summarised into PA energy expenditure (PAEE, in $\mathrm{kJ} / \mathrm{kg} / \mathrm{d}$ ), whilst minimising diurnal information bias caused by non-wear periods (segments of non-physiological data). Data from participants who did not complete individual calibration were processed using an age, sex, beta-blocker, and sleeping heart rate adjusted group calibration equation for the translation of heart-rate into activity intensity [19]. Quantification of plasma vitamin $\mathrm{C}$, a robust measure of fruit and vegetable intake, was assessed at baseline and one-year using a Fluoroskan Ascent FL fluorometer [20,21].

Self-reported PA was assessed at baseline and one year using the validated EPAQ2 questionnaire [22] and expressed as total metabolic equivalent task (MET) hours per day. Dietary intake was assessed at baseline and one year using a validated food-frequency questionnaire (FFQ) [21]. The FFQ questionnaire includes questions about usual consumption of 130 foods, assessed with a 9-point scale ranging from "never or less than once/ month" to "6 times per day"; and additional free text questions to categorise breakfast cereals, total fat and fatty acid consumption. The data are then converted into an amount for each nutrient profile and average daily nutrient intake, by reference to a regularly updated reference source for the nutritional content of food products. We used self-reported fat intake (grams/day), energy intake ( $\mathrm{kcal} /$ day), fruit intake (grams/day) and vegetable intake (grams/day).

\section{Psychological measures}

Anxiety was measured using the six item Spielberger short form State Anxiety Inventory (STAI) [23], with higher scores indicating higher state anxiety (baseline Cronbach's $\alpha=0.79$ ). Self-rated general health was measured using a single item on a 5-point Likert-type scale ranging from 'excellent' to 'poor', with a higher score indicating worse health.

A questionnaire based on the Theory of Planned Behaviour (TPB) [24] assessed intention to become more active and to eat a lower fat diet (e.g. 'I intend to be more physically active/eat a lower fat diet in the next 12 months'), perceived control (e.g. 'I am confident that I could be more physically active/eat a lower fat diet in the next 12 months, if I wanted to') and beliefs about these behaviours (e.g. 'If I was more physically active/eat a lower fat diet in the next 12 months, it is likely that that my health would improve'). Two items were used for each construct measured on a 5-point Likert-type scales ranging from 'strongly disagree' to 'strongly agree', with higher scores indicating more positive beliefs. Baseline Cronbach's alpha indicated satisfactory reliability of the scales (range from 0.77 to 0.89 ). To assess beliefs about diabetes consequences (e.g. 'My diabetes is a serious condition', Cronbach's $\alpha=0.74$ ) and treatment control (e.g. 'My treatment can control my diabetes', Cronbach's $\alpha=0.56$ ) subscales (11 items) of the Illness Perception Questionnaire-Revised (IPQ-R) were used [25]. The items were measured on a 5-point Likert-type scale ranging from 'strongly disagree' to 'strongly agree', with higher scores indicating stronger perceptions of diabetes consequences and treatment effectiveness.

\section{Data analyses}

Trial analyses showed that the behaviour change intervention did not lead to change in health behaviours or cardiovascular risk factors over and above intensive treatment alone [26]. Consequently, the two trial arms were pooled and a cohort analysis conducted. Descriptive characteristics were summarised using means $( \pm$ SDs $)$ or frequencies. We compared change in health behaviours between baseline and follow-up separately for men and women using a paired t-test for continuous data. Multivariable linear regression analysis was conducted to examine associations between the baseline predictors and health behaviours at one year, adjusting for baseline health behaviour (except for PAEE), trial group and all predictor variables. Tolerance statistics and variance inflation factors were used to test for multicollinearity and were within acceptable limits for all variables. The residuals of all regression models were examined to ensure that they were approximately normally distributed. We analysed change by including values of outcomes at one year in the regression model, 
adjusting for baseline values [27]. Sensitivity analyses showed that using a change score whilst adjusting for baseline values produced identical beta coefficients and p-values, except for the baseline covariate. All regression results are presented as unstandardised $\beta$-coefficients. Statistical analyses were performed using Stata/SE 12.0 (Stata-Corp, College Station, TX) and SPSS for Windows 19.0 (SPSS, Inc., Chicago, IL). Statistical significance was set at $P<0.05$.

\section{Results}

The mean age of participants was 60 years, $62 \%$ were male and the cohort was largely Caucasian (Table 1). The cohort exhibited an adverse cardiovascular risk profile with large waist circumferences and elevated systolic blood pressure, $\mathrm{HbA}_{1 \mathrm{c}}$ and total cholesterol values. Half of the participants had screen-detected diabetes and half were clinically diagnosed in the previous three years. Participants reported relatively strong intentions, perceived behavioural control, and behavioural beliefs towards changing behaviour, high diabetes treatment control perception, good general health, and relatively low state anxiety. There were no significant baseline differences between those attending the one-year health assessment and those who did not $(\mathrm{n}=23)$ for age, sex, social class, waist circumference, total cholesterol, and for the majority of psychological predictors. However, those who did not attend follow-up had a higher baseline $\mathrm{HbA}_{1 \mathrm{c}}$ (mean $7.8 \pm 1.88 \%$ ) compared to those who did attend $(7.1 \pm 1.44 \%, p=0.032)$.

Health behaviours at one-year follow-up and change over the year

Men had higher levels of PAEE than women at one year. Only women reported significant increases in self-reported PA from baseline to one year $(0.85$ metabolic equivalent $\mathrm{h} / \mathrm{d}$ which is equivalent to 13 $\mathrm{min} /$ brisk walking/d). Both sexes reported reduced energy and fat intake, and increased fruit intake. Men also reported increases in vegetable intake. There were corresponding increases in plasma vitamin $\mathrm{C}$ levels in both men and women from baseline to follow-up (Table 2).

\section{Multivariable predictors of health behaviour change and levels}

Younger patients, men, those with smaller waist circumference and with lower systolic blood pressure and higher diastolic blood pressure at baseline had higher PAEE levels at one year.

Women and patients with screen-detected diabetes were more likely to exhibit a larger increase in plasma vitamin C. Younger patients and those with clinically diagnosed diabetes were more likely to report larger
Table 1 Baseline socio-demographic, clinical and psychological characteristics of the ADDITION-Plus cohort ${ }^{a}$

\begin{tabular}{ll}
\hline Variables & Mean \pm SD \\
\hline Socio-demographic characteristics & \\
Age (years), $\mathrm{n}$ (mean \pm SD) & $478(59.7 \pm 7.5)$ \\
Male gender, $\mathrm{n}(\%)$ & $298(62.3)$ \\
Full-time education finished at >16 years, $\mathrm{n}(\%)$ & $291(61.7)$ \\
In full- or part-time employment, $\mathrm{n}(\%)$ & $245(51.4)$ \\
Married, $\mathrm{n}(\%)$ & $359(75.4)$ \\
Social class, $\mathrm{n}(\%)$ & \\
Managerial/professional occupations & $184(39.0)$ \\
Intermediate occupations & $120(25.4)$ \\
Routine/manual occupations & $168(35.6)$ \\
Caucasian ethnicity, $\mathrm{n}(\%)$ & $466(97.5)$ \\
Clinical characteristics & \\
Waist circumference (cm), $\mathrm{n}$ & $477(110.8 \pm 13.8)$ \\
Systolic blood pressure (mmHg), $\mathrm{n}$ & $478(136.1 \pm 19.23)$ \\
Diastolic blood pressure (mmHg), $\mathrm{n}$ & $478(80.3 \pm 10.42)$ \\
HbA ${ }_{1 \mathrm{c}}(\%), \mathrm{n}$ & $472(7.1 \pm 1.47)$ \\
Total cholesterol (mmol/l), $\mathrm{n}$ & $474(4.9 \pm 1.08)$ \\
Screen-detected type 2 diabetes, $\mathrm{n}(\%)$ & $239(50.0)$
\end{tabular}

Psychological characteristics (1 to 5)

Intention

$\begin{array}{ll}\text { Physical activity, } \mathrm{n} & 463(3.7 \pm 0.78)\end{array}$

Lower fat diet, $\mathrm{n} \quad 464(3.7 \pm 0.78)$

Perceived behavioural control

$\begin{array}{ll}\text { Physical activity, } \mathrm{n} & 463(3.8 \pm 0.86)\end{array}$

$\begin{array}{ll}\text { Lower fat diet, } \mathrm{n} & 465(3.7 \pm 0.87)\end{array}$

Behavioural beliefs

$\begin{array}{ll}\text { Physical activity, } \mathrm{n} & 467(4 \pm 0.68)\end{array}$

Lower fat diet, $\mathrm{n} \quad 464(3.8 \pm 0.73)$

Illness perception (1 to 5)

Diabetes treatment control, $\mathrm{n} \quad 451(3.8 \pm 0.49)$

Diabetes consequences, $\mathrm{n} \quad 454(2.9 \pm 0.65)$

State anxiety (20 to 80), $\mathrm{n} \quad 467(32.5 \pm 11.29)$

Self-rated health (1 to 5), $\mathrm{n} \quad 468(3.2 \pm 0.84)$

Values are means \pm SD unless otherwise indicated.

${ }^{a}$ Sample sizes differ due to missing data.

declines in their fat intake. Younger patients also reported larger decreases in energy intake. Screen-detected patients and those reporting better health at baseline were more likely to report increases in their fruit intake. There were no significant associations between any baseline predictors and change in self-reported PA and vegetable intake. Attitudes, beliefs and anxiety levels did not predict change in health behaviours in multivariable analyses (Table 3 ). 
Table 2 Change in health behaviours between baseline and one year in the ADDITION-Plus cohort stratified by sex ${ }^{a}$

\begin{tabular}{|c|c|c|c|c|c|c|}
\hline \multirow[t]{2}{*}{ Variables } & \multicolumn{3}{|l|}{ Men } & \multicolumn{3}{|l|}{ Women } \\
\hline & Baseline & 1 year & Difference $(95 \% \mathrm{Cl})$ & Baseline & 1 year & Difference $(95 \% \mathrm{Cl})$ \\
\hline \multicolumn{7}{|l|}{$\begin{array}{l}\text { Objectively measured } \\
\text { health behaviours }\end{array}$} \\
\hline $\begin{array}{l}\text { Physical activity } \\
\text { energy expenditure } \\
(\mathrm{kJ} / \mathrm{kg} / \mathrm{d}), \mathrm{n}\end{array}$ & Not measured & $270,37.8 \pm 18.1$ & - & Not measured & $160,29 \pm 13.6$ & - \\
\hline $\begin{array}{l}\text { Plasma vitamin C } \\
(\mu \mathrm{mol} / \mathrm{l}), \mathrm{n}\end{array}$ & $260,47.1 \pm 19.1$ & $260,49.9 \pm 21.9$ & $2.78(0.21,5.35)^{*}$ & $152,55.7 \pm 20.8$ & $152,59.6 \pm 20.8$ & $3.91(0.37,7.45)^{*}$ \\
\hline \multicolumn{7}{|l|}{$\begin{array}{l}\text { Self-reported health } \\
\text { behaviours }\end{array}$} \\
\hline $\begin{array}{l}\text { Total physical activity } \\
\text { (MET h/d), n }\end{array}$ & $280,13.2 \pm 8.2$ & $280,13.5 \pm 8.4$ & $0.25(-0.57,1.07)$ & $168,10.1 \pm 5.5$ & $168,10.9 \pm 5.7$ & $0.85(0.11,1.59)^{*}$ \\
\hline Fat intake (g/day), n & $279,71.5 \pm 30.6$ & $279,61.5 \pm 22.2$ & $-10.04(-13.06,-7.01)^{* * *}$ & $166,63.4 \pm 28.2$ & $166,58.6 \pm 23.5$ & $-4.82(-8.69,-0.95)^{*}$ \\
\hline $\begin{array}{l}\text { Energy intake } \\
\text { (kcal/d), n }\end{array}$ & $279,2004 \pm 657$ & $279,1790 \pm 498$ & $-214(-279,-149)^{* * *}$ & $166,1776 \pm 594$ & $166,1681 \pm 504$ & $-95(-178,-12)^{*}$ \\
\hline Fruit intake $(\mathrm{g} / \mathrm{d}), \mathrm{n}$ & $261,253.4 \pm 199.7$ & $261,292.7 \pm 207.3$ & $39.26(12.64,65.89)^{* *}$ & $155,303 \pm 189.4$ & $155,343 \pm 229.3$ & $40.03(5.85,74.2)^{*}$ \\
\hline Vegetable intake $(\mathrm{g} / \mathrm{d}), \mathrm{n}$ & $259,209.8 \pm 114.3$ & $259,229.2 \pm 146$ & $19.41(5.19,33.64)^{* *}$ & $145,277.5 \pm 180.9$ & $145,277.6 \pm 133.7$ & $0.09(-26.17,26.36)$ \\
\hline
\end{tabular}

\section{Discussion}

Younger age and diabetes detected through screening emerged as the most consistent predictors of dietary change over the year of study, and objective physical activity at one year. Our finding that younger patients engaged in higher levels of physical activity supports previous literature [28]. Patients with screen-detected diabetes were diagnosed more recently than clinically diagnosed patients. The diagnosis may have acted as a cue to adopt healthier behaviours over the year of our study, whereas patients with clinically diagnosed diabetes may have faced challenges to maintain any changes in behaviour made soon after diagnosis. Our findings contribute to previous literature by suggesting the existence of a window of opportunity to facilitate behaviour change early in the disease trajectory.

There were significant improvements in self-reported PA in women, and in self-reported and objectively measured dietary variables in men and women over one year in this cohort of recently diagnosed diabetes patients. Intervention studies focusing on lifestyle change among people with recently diagnosed $[7,11]$ and established diabetes have also reported positive changes in selfreported PA and diet over 12 months [29].

There were significant associations between younger age, male sex, a smaller waist circumference, and lower systolic blood pressure values at baseline and higher PAEE levels at one year. These results are partially in agreement with other studies. A study among offspring of people with diabetes (mean age 40 years) identified male sex and a higher level of baseline fitness as predictors of change in objectively measured PA [30]. A review of correlates of adults' participation in selfreported PA showed that PA participation was consistently higher among men than women and was inversely associated with age [28]. A cohort study revealed that adults ( $\geq 55$ years) with a large waist circumference were more likely to be physically inactive than those with smaller waists [31]. An association was also observed between baseline diastolic blood pressure and PAEE at one year, but this was of borderline statistical significance.

We did not find any significant baseline predictors of change in self-reported PA. Previous studies identified the following predictors of self-reported PA in patients with recently diagnosed diabetes: age [12], sex [12], BMI [11,13], future-oriented thinking [12], proactive competence [11], and baseline exercise behaviour [11]. These findings are similar to our results regarding objectively measured PA levels at one year, but not with change in self-reported PA. Differences may be due to length of follow-up (short-term predictors of change may differ from long-term predictors), the larger age ranges targeted by other interventions, and the difference in measurement method $[12,13]$.

Greater increases in plasma vitamin $\mathrm{C}$ levels were observed in women, which is consistent with other studies that have shown higher plasma vitamin $C$ concentrations in women $[32,33]$. We observed a greater change in plasma vitamin $\mathrm{C}$ levels and in fruit intake among patients with screen-detected diabetes than in clinically diagnosed patients. This might reflect a greater capacity for change in dietary behaviour in the first year after 
Table 3 Multivariable associations between baseline characteristics and health behaviours at one year in the ADDITION-PIus cohort

\begin{tabular}{|c|c|c|c|c|c|c|c|}
\hline Potential predictors & $\begin{array}{l}\text { PAEE }(\mathrm{kJ} / \mathrm{kg} / \mathrm{d}), \\
\mathrm{n}=378\end{array}$ & $\begin{array}{l}\text { Plasma vitamin C } \\
(\mu \mathrm{mol} / \mathrm{l}), \mathrm{n}=363\end{array}$ & $\begin{array}{l}\text { Self-reported physical } \\
\text { activity (MET h/d), } n=390\end{array}$ & $\begin{array}{l}\text { Self-reported fat } \\
\text { intake }(g / d), n=390\end{array}$ & $\begin{array}{l}\text { Self-reported energy } \\
\text { intake (kcal/d), } n=390\end{array}$ & $\begin{array}{l}\text { Self-reported fruit } \\
\text { intake }(g / d), n=365\end{array}$ & $\begin{array}{l}\text { Self-reported vegetabl } \\
\text { intake }(g / d), n=358\end{array}$ \\
\hline \multicolumn{8}{|l|}{$\begin{array}{l}\text { Socio-demographic } \\
\text { characteristics }\end{array}$} \\
\hline Age (years) & $-0.72(-0.98,-0.47)^{* * *}$ & $0.3(-0,0.6)$ & $-0.06(-0.16,0.33)$ & $-0.43(-0.72,-0.13)^{* *}$ & $-6.62(-13.2,-0.05)^{*}$ & $-1.17(-4.33,1.98)$ & $-0.52(-2.54,1.49)$ \\
\hline Sex (women = ref.) & $10.9(7.35,14.51)^{* * *}$ & $-5.52(-9.81,-1.22)^{*}$ & $0.46(-0.88,1.81)$ & $0.19(-4.39,4.01)$ & $9.94(-83.91,103.78)$ & $-37(-82.36,8.34)$ & $-4.46(-34.01,25.09)$ \\
\hline \multicolumn{8}{|l|}{$\begin{array}{l}\text { Social class (managerial/ } \\
\text { professional occ. = ref.) }\end{array}$} \\
\hline Intermediate & $0.63(-3.53,4.79)$ & $0.36(-4.69,5.41)$ & $0.41(-1.13,1.95)$ & $0.82(-4.17,5.81)$ & $11.4(-99.3,122.07)$ & $-16.9(-70.09,36.34)$ & $-0.09(-33.85,33.66)$ \\
\hline Routine/manual & $2.26(-1.47,6)$ & $-3.24(-7.7,1.23)$ & $0.21(-1.18,1.59)$ & $-1.36(-5.75,3.03)$ & $-72.3(-169.61,24.97)$ & $-4.5(-52.03,43.02)$ & $-3.06(-33.0,26.87)$ \\
\hline \multicolumn{8}{|l|}{ Clinical characteristics } \\
\hline Waist circumference (cm) & $-0.33(-0.45,-0.2)^{* * *}$ & $-0.1(-0.26,0.05)$ & $-0.03(-0.07,0.02)$ & $-0.11(-0.26,0.04)$ & $-2.97(-6.28,0.34)$ & $0.49(-1.11,2.08)$ & $-0.32(-1.33,0.69)$ \\
\hline $\begin{array}{l}\text { Systolic blood } \\
\text { pressure (mmHg) }\end{array}$ & $-0.18(-0.31,-0.06)^{* *}$ & $-0.05(-0.2,0.1)$ & $0.02(-0.02,0.07)$ & $-0.09(-0.24,0.06)$ & $-1.2(-4.49,2.08)$ & $0.9(-0.68,2.49)$ & $-0.01(-1.01,0.98)$ \\
\hline $\begin{array}{l}\text { Diastolic blood } \\
\text { pressure (mmHg) }\end{array}$ & $0.23(0,0.46)^{*}$ & $0.03(-0.25,0.31)$ & $-0.01(-0.1,0.07)$ & $0.06(-0.21,0.34)$ & $0.68(-5.34,6.69)$ & $-1.56(-4.45,1.32)$ & $-0.24(-2.06,1.58)$ \\
\hline $\mathrm{HbA}_{1 c}(\%)$ & $-0.25(-1.36,0.86)$ & $-0.29(-1.67,1.09)$ & $0.31(-0.11,0.72)$ & $-0.37(-1.71,0.98)$ & $-16.0(-45.67,13.67)$ & $-0.95(-15.41,13.51)$ & $-1.77(-11.64,8.1)$ \\
\hline Cholesterol (mmol/l) & $0.37(-1.22,1.96)$ & $-1.61(-3.54,0.33)$ & $-0.28(-0.88,0.32)$ & $-0.72(-2.62,1.18)$ & $-32.8(-74.95,9.31)$ & $-18.9(-39.15,1.45)$ & $3.91(-9.19,17.02)$ \\
\hline $\begin{array}{l}\text { Diabetes diagnosis } \\
\text { (clinically diagnosed = } \\
\text { ref.) }\end{array}$ & $2.91(-0.59,6.42)$ & $6.09(1.74,10.43)^{* *}$ & $1.04(-0.27,2.35)$ & $-4.9(-9.21,-0.6)^{*}$ & $-56.5(-151.76,38.81)$ & $74.2(27.92,120.41)^{* *}$ & $10.2(-19.43,39.82)$ \\
\hline \multicolumn{8}{|l|}{$\begin{array}{l}\text { Psychological } \\
\text { characteristics }\end{array}$} \\
\hline \multicolumn{8}{|l|}{ Intention } \\
\hline Physical activity & $-0.37(-3.41,2.68)$ & - & $0.69(-0.46,1.84)$ & - & - & - & - \\
\hline Lower fat diet & - & $-1.89(-5.68,1.89)$ & - & $-1.01(-4.81,2.78)$ & $-26.2(-110.29,57.83)$ & $-20.8(-62.08,20.44)$ & $22.5(-3.14,48.04)$ \\
\hline \multicolumn{8}{|l|}{$\begin{array}{l}\text { Perceived } \\
\text { behavioural control }\end{array}$} \\
\hline Physical activity & $1.04(-1.47,3.55)$ & - & $0.04(-0.9,0.98)$ & - & - & - & - \\
\hline Lower fat diet & - & $0.22(-2.86,3.3)$ & - & $-0.98(-4.04,2.09)$ & $-7.52(-75.32,60.27)$ & $17.7(-16.12,51.41)$ & $-5.49(-26.22,15.24)$ \\
\hline \multicolumn{8}{|l|}{ Behavioural beliefs } \\
\hline Physical activity & $-1.06(-4.13,2.02)$ & - & $-0.7(-1.84,0.43)$ & - & - & - & - \\
\hline Lower fat diet & - & $0.06(-3.67,3.79)$ & - & $0.62(-3.11,4.35)$ & $19.6(-62.88,102.09)$ & $-5.21(-45.29,34.87)$ & $-8.66(-34.28,16.95)$ \\
\hline \multicolumn{8}{|l|}{ IIIness perception (1 to 5) } \\
\hline $\begin{array}{l}\text { Diabetes treatment } \\
\text { control }\end{array}$ & $2.33(-1.25,5.91)$ & $3.7(-0.64,8.04)$ & $-0.38(-1.71,0.94)$ & $0.24(-3.99,4.48)$ & $9.49(-84.44,103.43)$ & $-3.08(-48.07,41.92)$ & $3.54(-24.58,31.67)$ \\
\hline
\end{tabular}


Table 3 Multivariable associations between baseline characteristics and health behaviours at one year in the ADDITION-Plus cohort (Continued)

\begin{tabular}{|c|c|c|c|c|c|c|c|}
\hline Diabetes consequences & $1.51(-1,4.03)$ & $1.43(-1.65,4.51)$ & $0.58(-0.38,1.53)$ & $-1.8(-4.89,1.29)$ & $6.62(-61.81,75.04)$ & $21.8(-11.66,55.18)$ & $13.1(-7.54,33.73)$ \\
\hline State anxiety (20 to 80) & $-0.07(-0.22,0.08)$ & $-0.12(-0.3,0.06)$ & $-0.04(-0.09,0.02)$ & $-0.06(-0.25,0.12)$ & $-1.2(-5.26,2.86)$ & $-0.81(-2.74,1.13)$ & $0.15(-1.07,1.38)$ \\
\hline Self-rated health (1 to 5) & $-0.58(-2.73,1.58)$ & $-0.6(-3.19,1.98)$ & $-0.19(-1.0,0.62)$ & $0.46(-2.08,3)$ & $-2.66(-59.09,53.76)$ & $-28(-55.33,-0.69)^{*}$ & $-10.3(-27.9,7.36)$ \\
\hline
\end{tabular}

Values are unstandardised b-coefficients $(95 \%$ confidence interval).

All models were simultaneously adjusted for included predictors as well as for baseline behaviour (except for PAEE) and trial arm.

All models were simultaneously adjusted for

, not included in the model.

${ }^{*} p<0.05,{ }^{* *} p<0.01,{ }^{* * *} p<0.00 .1$. 
diagnosis among screen-detected patients, while clinically diagnosed patients have lived with the condition for longer and may have already made significant changes to their diet. While the difference in the increase in plasma vitamin $C$ levels between screen- and clinically-diagnosed patients was small $(6 \mu \mathrm{mol} / \mathrm{l})$, the difference between the 25th and 75th percentiles was $24 \mu \mathrm{mol} / \mathrm{l}$, suggesting that patients in the top quartile of plasma vitamin $C$ consumed one more portion of fruit and vegetables per day compared with those in the bottom quartile. A similar difference was seen in self-reported fruit intake, where screen-detected diabetes patients increased on average $74 \mathrm{~g} / \mathrm{d}$ (which equals a fresh apricot) compared with clinically diagnosed diabetes patients.

ADDITION-Plus participants who reported better health at baseline were also more likely to report increases in fruit intake. A cross-sectional study among US adults indicated that the odds of consuming $\geq 5$ servings of fruits and vegetables per day were higher among those who rated their health as excellent/very good compared to those who rated their health as poor [34]. We did not observe any significant associations between baseline predictors and change in self-reported vegetable intake in multivariable analysis.

Younger patients were more likely to report a greater reduction in fat and energy intake. Other studies among patients with recently diagnosed diabetes showed that only baseline dietary behaviour [11,12] and proactive competence [11] predicted fat consumption at followup. Having a clinical diagnosis of diabetes was a predictor of greater decrease in fat intake (approx. $5 \mathrm{~g} / \mathrm{d}$ which equals, for example, one teaspoon of mayonnaise) indicating a better management of fat intake among patients who lived with the condition for longer.

Intention, perceived behavioural control and beliefs about becoming more physically active and eating a low fat diet did not predict change in objectively measured or self-reported behaviours in the ADDITIONPlus cohort. These findings replicate results in a study by Thoolen et al. [11] in which exercise and diet intentions did not predict these behaviours at follow-up in patients with recently diagnosed diabetes. Lack of associations is unlikely to be due to lack of power as our sample size was large compared to most studies in this area. Instead it may be due to inaccurate or unrealistic beliefs at baseline when patients had limited experience with behaviour change, the one-year interval between measurement of beliefs and behaviour, or behaviour change through automatic routes (e.g. activation of previous goals) rather than reflective routes [35]. Although previous research suggested that the TPB is useful for the prediction of health behaviours in the general population [36], studies of prediction of behaviour change using the TPB are few, and findings for people at risk for diabetes are inconsistent $[37,38]$. Our results suggest that the TPB might not be a useful framework for predicting changes in health-related behaviours in individuals with recently diagnosed diabetes. Other psychological predictors also did not predict change in health-related behaviours in our cohort. This might be partially attributed to the low reliability of some measures (Cronbach's alpha at baseline was 0.56 for treatment control) or common method variance [39]. When a behaviour and its determinants are measured using the same method e.g. by self-report questionnaire, associations may be due, at least in part, to commonality in response patterns to these measures. When the behaviour is measured by a different method, e.g. objectively, part of the correlation explained by common method variance disappears, leading to lower or non-significant associations. Some studies have shown, for example, that psychological determinants of dietary behaviour predict self-rated fruit and vegetable intake (asking people to rate their own fruit and vegetable consumption) better than intake assessed by FFQ (general food intake questionnaire) $[40,41]$. Finally, since it has been shown that environmental factors are significantly related to health behaviours [28], and that social support might be important in health behaviour change $[28,42]$, it would be desirable to incorporate these variables as correlates of behaviour change in future studies.

The present study has several strengths. ADDITIONPlus included objective and self-report measurement of two key health behaviours over 12 months in a welldefined group of patients at high cardiovascular risk who could benefit from positive changes in diet and PA. The use of an objective measure of PA, which has been extensively validated in the laboratory and during freeliving conditions $[43,44]$, reduces the error and bias commonly associated with self-report measures. There was a high follow-up rate (95\%) and a wide range of potential predictors from a variety of domains were examined. The study also has several limitations. While the sample was population-based, it was largely Caucasian and middle-aged, which restricts generalizability to other populations. Other limitations include the fact that PAEE was only measured at one year, and that self-reported health behaviours may be subject to recall and social desirability bias. Furthermore, we also explored a number of associations and conducted multiple significance tests, which mean that our results should be interpreted with caution as some significant associations may have occurred by chance (alpha inflation).

\section{Conclusions}

We observed significant improvements in self-reported PA in women, and in self-reported and objectively measured 
dietary variables in men and women over one year in this cohort of recently diagnosed diabetes patients. Younger age, female sex and a screen-detected diagnosis of diabetes were strong predictors of improved dietary behaviours, suggesting that older patients, men and those with a longer duration of diabetes may need more support for dietary change. We did not identify any baseline predictors of self-reported physical activity change but did observe associations with objectively measured PA at one year. We recommend that future studies use objective measurement of health behaviours and that researchers add predictors beyond the individual level. Our results support a focus on establishing healthy lifestyle changes early in the diabetes disease trajectory.

\section{Competing interests}

No potential conflicts of interest relevant to this article were reported by the authors of this paper.

\section{Authors' contributions}

WH, SS and RKS conceived the study question. LK analysed and interpreted the data, and produced the first draft of the manuscript. All authors contributed to the drafting of the manuscript, critically revised the manuscript for important intellectual content and approved the final version.

\section{Acknowledgments}

ADDITION-Cambridge was supported by the Wellcome Trust (grant reference No G061895) the Medical Research Council (grant Reference no: G0001164), National Health Service R\&D support funding (including the Primary Care Research and Diabetes Research Networks) and the National Institute for Health Research. We received an unrestricted grant from University of Aarhus, Denmark to support the ADDITION-Cambridge trial. Bio-Rad provided equipment to undertake capillary glucose screening by $\mathrm{HbA}_{1 \mathrm{c}}$ in general practice. ALK \& SJG were founding members of the National Institute for Health Research (NIHR) School for Primary Care Research. ALK is a NIHR Senior Investigator. The Primary Care Unit is supported by NIHR Research funds. SJG has received support from the Department of Health NIHR Programme Grant funding scheme [RP-PG-0606-1259]. The views expressed in this publication are those of the authors and not necessarily those of the Department of Health. The funders of the study had no role in study design, data collection, analysis and interpretation or writing of the report. The corresponding author had full access to all the study data and final responsibility for submission for publication.

LK was supported by the German Research Foundation (DFG) Grant KU 3056/1-1.

\section{Author details}

${ }^{1}$ MRC Epidemiology Unit, University of Cambridge, Box 285, Addenbrooke's Hospital, Hills Road, Cambridge, CB2 0QQ, UK. ${ }^{2}$ The Primary Care Unit, Cambridge Institute of Public Health, University of Cambridge, Robinson Way, Cambridge CB2 OSR, UK.

Received: 27 March 2013 Accepted: 19 September 2013

Published: 23 October 2013

\section{References}

1. Thomas DE, Elliott EJ, Naughton GA: Exercise for type 2 diabetes mellitus. Cochrane Database Syst Rev 2006, Issue 3: . Art. No.: CD002968. DOI:10.1002/ 14651858.CD002968.pub2.

2. Hu FB, Stampfer MJ, Solomon C, Liu S, Colditz GA, Speizer FE, Willett WC, Manson JE: Physical activity and risk for cardiovascular events in diabetic women. Ann Intern Med 2001, 134:96-105.

3. Stratton IM, Adler Al, Neil HA, Matthews DR, Manley SE, Cull CA, Hadden D, Turner RC, Holman RR: Association of glycaemia with macrovascular and microvascular complications of type 2 diabetes (UKPDS 35): prospective observational study. BMJ 2000, 321:405-412.
4. Nazimek-Siewniak B, Moczulski D, Grzeszczak W: Risk of macrovascular and microvascular complications in Type 2 diabetes: results of longitudinal study design. J Diabetes Complications 2002, 16:271-276.

5. Khunti K, Gray LJ, Skinner T, Carey ME, Realf K, Dallosso H, Fisher H, Campbell M, Heller S, Davies MJ: Effectiveness of a diabetes education and self management programme (DESMOND) for people with newly diagnosed type 2 diabetes mellitus: three year follow-up of a cluster randomised controlled trial in primary care. BMJ 2012, 344:e2333.

6. Davies MJ, Heller S, Skinner TC, Campbell MJ, Carey ME, Cradock S, Dallosso HM, Daly H, Doherty Y, Eaton S, et al: Effectiveness of the diabetes education and self management for ongoing and newly diagnosed (DESMOND) programme for people with newly diagnosed type 2 diabetes: cluster randomised controlled trial. BMJ 2008, 336:491-495.

7. Andrews RC, Cooper AR, Montgomery AA, Norcross AJ, Peters TJ, Sharp DJ, Jackson N, Fitzsimons K, Bright J, Coulman K, et al: Diet or diet plus physical activity versus usual care in patients with newly diagnosed type 2 diabetes: the Early ACTID randomised controlled trial. Lancet 2011, 378:129-139.

8. Nathan DMBJB, Davidson MB, Ferrannini E, Holman RR, Sherwin R, Zinman B, American Diabetes A, European Association for the Study of D: Medical management of hyperglycemia in type 2 diabetes: a consensus algorithm for the initiation and adjustment of therapy: a consensus statement of the American Diabetes Association and the European Association for the Study of Diabetes. Diabetes Care 2009, 32:193-203.

9. Broadbent E, Donkin L, Stroh JC: Illness and treatment perceptions are associated with adherence to medications, diet, and exercise in diabetic patients. Diabetes Care 2011, 34:338-340.

10. Murphy E, Kinmonth AL: No symptoms, no problem? Patients' understandings of non-insulin dependent diabetes. Fam Pract 1995, 12:184-192.

11. Thoolen BJ, de Ridder D, Bensing J, Gorter K, Rutten G: Beyond good intentions: the role of proactive coping in achieving sustained behavioural change in the context of diabetes management. Psychol Health 2009, 24:237-254.

12. Hall PA, Fong GT, Cheng AY: Time perspective and weight management behaviors in newly diagnosed Type 2 diabetes: a mediational analysis. J Behav Med 2011, 35:569-580.

13. Plotnikoff RC, Lippke S, Karunamuni N, Eves N, Courneya KS, Sigal R, Birkett NJ: Co-morbidity, functionality and time since diagnosis as predictors of physical activity in individuals with type 1 or type 2 diabetes. Diabetes Res Clin Pract 2007, 78:115-122.

14. Griffin SJ, Simmons RK, Williams KM, Prevost AT, Hardeman W, Grant J, Whittle F, Boase S, Hobbis I, Brage S, et al: Protocol for the ADDITION-Plus study: a randomised controlled trial of an individually-tailored behaviour change intervention among people with recently diagnosed type 2 diabetes under intensive UK general practice care. BMC Public Health 2011, 11:211.

15. Echouffo-Tcheugui JB, Simmons RK, Williams KM, Barling RS, Prevost AT, Kinmonth AL, Wareham NJ, Griffin SJ: The ADDITION-Cambridge trial protocol: a cluster - randomised controlled trial of screening for type 2 diabetes and intensive treatment for screen-detected patients. BMC Public Health 2009, 9:136.

16. Diabetes in adults quality standard. [http://publications.nice.org.uk/diabetesin-adults-quality-standard-qs6.

17. Brage S, Brage N, Franks PW, Ekelund U, Wareham NJ: Reliability and validity of the combined heart rate and movement sensor Actiheart. Eur J Clin Nutr 2005, 59:561-570.

18. Stegle O, Fallert SV, MacKay DJ, Brage S: Gaussian process robust regression for noisy heart rate data. IEEE Trans Biomed Eng 2008, 55:2143-2151.

19. Brage S, Brage N, Franks PW, Ekelund U, Wong MY, Andersen LB, Froberg K, Wareham NJ: Branched equation modeling of simultaneous accelerometry and heart rate monitoring improves estimate of directly measured physical activity energy expenditure. J Appl Physiol 2004, 96:343-351.

20. Khaw KT, Wareham NJ, Bingham S, Luben R, Welch A, Day N: Association of hemoglobin A1c with cardiovascular disease and mortality in adults: the European prospective investigation into cancer in Norfolk. Ann Intern Med 2004, 141:413-420.

21. Bingham SA, Gill C, Welch A, Cassidy A, Runswick SA, Oakes S, Lubin R, Thurnham DI, Key TJ, Roe L, et al: Validation of dietary assessment 
methods in the UK arm of EPIC using weighed records, and 24-hour urinary nitrogen and potassium and serum vitamin $\mathrm{C}$ and carotenoids as biomarkers. Int J Epidemiol 1997, 26(Suppl 1):S137-S151.

22. Wareham NJ, Rennie KL: The assessment of physical activity in individuals and populations: why try to be more precise about how physical activity is assessed? Int J Obes Relat Metab Disord 1998, 22(Suppl 2):S30-S38.

23. Marteau TM, Bekker $\mathrm{H}$ : The development of a six-item short-form of the state scale of the Spielberger State-Trait Anxiety Inventory (STAI). Br J Clin Psychol 1992, 31(Pt 3):301-306.

24. Constructing a Theory of Planned Behaviour Questionnaire: Brief Description of the Theory of Planned Behaviour. http://people.umass.edu/aizen/pdf/tpb. measurement.pdf.

25. Moss-Morris R, Weinman J, Petrie KJ, Horne R, Cameron LD, Buick D: The revised illness perception questionnaire (IPQ-R). Psychol Health 2002, 17:1-16.

26. Griffin S, Simmons RK, Prevost AT, Williams KM, Hardeman W, Sutton S, Ekelund U, Wareham NJ, Kinmonth AL: Does a facilitator-led, individuallytailored behaviour change intervention improve outcomes for people with recently diagnosed type 2 diabetes in UK general practice? One-year reults from ADDITION-Plus randomised controlled trial (clinical trial registration number ISRCTN99175498), In submission.

27. Twisk JWR: Longitudinal studies with two measurements: the definition and analysis of change, Applied Longitudinal Data Analysis for Epidemiology. Cambridge: Cambridge University Press; 2009.

28. Trost SG, Owen N, Bauman AE, Sallis JF, Brown W: Correlates of adults' participation in physical activity: review and update. Med Sci Sports Exerc 2002, 34:1996-2001

29. Clark M, Hampson SE, Avery L, Simpson R: Effects of a tailored lifestyle self-management intervention in patients with type 2 diabetes. BrJ Health Psychol 2004, 9:365-379.

30. Simmons RK, van Sluijs EM, Hardeman W, Sutton S, Griffin SJ, ProActive project t: Who will increase their physical activity? Predictors of change in objectively measured physical activity over 12 months in the ProActive cohort. BMC Public Health 2010, 10:226.

31. Jacobs EJ, Newton CC, Wang Y, Patel AV, McCullough ML, Campbell PT, Thun MJ, Gapstur SM: Waist circumference and all-cause mortality in a large US cohort. Arch Intern Med 2010, 170:1293-1301.

32. Will JC, Ford ES, Bowman BA: Serum vitamin C concentrations and diabetes: findings from the Third National Health and Nutrition Examination Survey, 1988-1994. Am J Clin Nutr 1999, 70:49-52.

33. Khaw KT, Bingham S, Welch A, Luben R, Wareham N, Oakes S, Day N: Relation between plasma ascorbic acid and mortality in men and women in EPIC-Norfolk prospective study: a prospective population study. European Prospective Investigation into Cancer and Nutrition. Lancet 2001, 357:657-663.

34. Erinosho TO, Thompson OM, Moser RP, Yaroch AL: Fruit and vegetable intake of US adults: comparing intake by mode of survey administration. J Am Diet Assoc 2011, 111:408-413.

35. Strack F, Deutsch R: Reflective and impulsive determinants of social behaviour. Pers Soc Psychol Rev 2004, 8:220-247.

36. Hagger MS, Chatzisarantis NLD, Biddle SJH: A meta-analytic review of the Theories of Reasoned Action and Planned Behavior in physical activity: predictive validity and the contribution of additional variables. J Sport Exerc Psychol 2002, 24:3-32.

37. Blue CL: Does the theory of planned behavior identify diabetes-related cognitions for intention to be physically active and eat a healthy diet? Public Health Nurs 2007, 24:141-150.

38. Hardeman W, Kinmonth AL, Michie S, Sutton S: Theory of planned behaviour cognitions do not predict self-reported or objective physical activity levels or change in the ProActive trial. Br J Health Psychol 2011, 16:135-150

39. Campbell DT, Fiske DW: Convergent and discriminant validation by the multitrait-multimethod matrix. Psychol Bull 1959, 56:81-105.

40. Brug J, Van Assema P, Kok G, Lenderink T, Glanz K: Self-rated dietary fat intake: association with objective assessment of fat, psychological factors, and intention to change. J Nutr Educ 1994, 26:218-223.

41. Lechner L, Brug J, De Vries H: Misconceptions of fruit and vegetable consumption: differences between objective and subjective estimation of intake. J Nutr Educ 1997, 29:313-320.

42. Greaves CJ, Sheppard KE, Abraham C, Hardeman W, Roden M, Evans PH, Schwarz P, Group IS: Systematic review of reviews of intervention components associated with increased effectiveness in dietary and physical activity interventions. BMC Public Health 2011, 11:119.

43. Crouter SE, Churilla JR, Bassett DR Jr: Accuracy of the Actiheart for the assessment of energy expenditure in adults. Eur J Clin Nutr 2008, 62:704-711.

44. Thompson D, Batterham AM, Bock S, Robson C, Stokes K: Assessment of low-to-moderate intensity physical activity thermogenesis in young adults using synchronized heart rate and accelerometry with branched-equation modeling. J Nutr 2006, 136:1037-1042.

doi:10.1186/1479-5868-10-118

Cite this article as: Kuznetsov et al:: Predictors of change in objectively measured and self-reported health behaviours among individuals with recently diagnosed type 2 diabetes: longitudinal results from the ADDITION-Plus trial cohort. International Journal of Behavioral Nutrition and Physical Activity 2013 10:118.

\section{Submit your next manuscript to BioMed Central and take full advantage of:}

- Convenient online submission

- Thorough peer review

- No space constraints or color figure charges

- Immediate publication on acceptance

- Inclusion in PubMed, CAS, Scopus and Google Scholar

- Research which is freely available for redistribution 